\title{
Synthesis and Morphological Characterization of Sodium and Calcium Clay Nanostructured Poly( $\varepsilon$-Caprolactam) [Nylon 6] Hybrids
}

\author{
S.M. Vega-Díaz ${ }^{1}$, F.J. Medellín-Rodríguez*,', S. Sánchez-Valdés² ${ }^{2}$ B. E. Handy ${ }^{1}$, J.M. Mata-Padilla ${ }^{1}$ \\ and O. Dávalos-Montoya
}

${ }^{I}$ Centro de Investigación y Estudios de Posgrado, Facultad de Ciencias Químicas, Universidad Autónoma de San Luís Potosí, Av. Dr. Manuel Nava 6, Zona Universitaria, San Luis Potosí, S.L.P. 78216, México. ${ }^{2}$ Centro de Investigación en Química Aplicada, Blvd. Enrique Reyna Hermosillo 140, Saltillo, Coah., 25100, México

\begin{abstract}
The synthesis and morphological characterization of Nylon 6 hybrids using the most common montmorillonite types, sodium and calcium, are reported. Two local nanoclays and a commercial, cation exchanged, reference were used in order to obtain the hybrid products. The local sodium and calcium nanoclays were first homoionized and then ion exchanged with surfactants, being the main purpose to obtain similar reaction precursors as the commercial clay. Both local clay precursors and commercial clay showed similar crystallographic structure and layer-to-layer spacing after all physicochemical treatments. The best reaction conditions were first determined and then a simple infra-red based technique was implemented with the purpose to obtain the molecular weight of the hybrid products. It was determined that, sodium, calcium, and commercial nanoclays render relatively similar molecular weights of nanoclay hybrids using identical synthesis conditions. Thermal analyses indicated the formation of two and three melting endotherms in all cases depending on the isothermal crystallization temperature. X-ray diffraction patterns displayed crystal plane truncation which is usually observed in nanoclay hybrids. Plane truncation depended on the nanoclays nature, although the highest truncation was observed with commercial and sodium nanoclays. X-rays dispersion results allowed to infer the partial formation of nonhybrid polymer depending on the type of clay, sodium nanoclay showing the lesser proportion, and as a consequence the highest hybridization. Transmission electron microscopy results corroborated the relative degree of exfoliation and nanoclay dispersion of the hybrid products.
\end{abstract}

Keywords: Nanoclay hybrids, Polymer morphology, Nylon 6.

\section{INTRODUCTION}

Hybrid Nylon 6 is one the first commercially produced clay nanostructured polymers whose reaction mechanisms are well known (Ke Elsevier 2005) [1]. Neat Nylon 6 is able to crystallize in two crystal habits, $\alpha$ and $\gamma$, depending on molecular characteristics and thermal conditions (Kyotani JPSP A 1972) [2]. Some reports (Gurato DMC 1974) [3], (Liberti JPSP A 1968) [4], (Arakawa JPS 1969) [5], (Valenti JPC 1973) [6], (Itoh JJAP 1975) [7], have indicated that, depending on molecular weight and crystallization conditions, Nylon 6 develops multiple melting on heating. Clay nanostructured Nylon 6 is usually obtained via in-situ polymerization of $\varepsilon$-caprolactam. It develops more complicated crystallization habits and, as a consequence, melting behavior. This is due to the chemical attachment of the macromolecules to the nanoclay surface. It has been reported for example (Wu PES 2002) [8], (Bertmer CM 2007) [9], that, under isothermal crystallization conditions, high nanoclay concentrations induce the formation of the $\alpha$ structure. Low nanoclay concentrations on the other hand tend to promote a mixture of $\alpha / \gamma$ crystal habits. A meta stable phase, similar to the $\gamma$ phase (Nair Macromol 2005) [10], and the formation of

*Address correspondence to this author at the Centro de Investigación y Estudios de Posgrado, Facultad de Ciencias Químicas, Universidad Autónoma de San Luís Potosí, Av. Dr. Manuel Nava 6, Zona Universitaria, San Luis Potosí, S.L.P.78216, México; E-mail: francmr@uaslp.mx a truncated $\alpha$ structure, have also been reported to occur in hybrid Nylon 6 (Wu PES 2002) [8] (Zapata-Espinosa Macromol 2005) [11]. Plane truncation involves planar diffraction decompensations due to substrate induced crystallization of the hybrid polymer molecules. The inorganic component in clay nanostructured Nylon 6 is usually montmorillonite which has received a great deal of attention because of its layer-like nature. As such, it provides a high surface to volume ratio, highly desired for practical applications, one example being gas barrier films. The crystallographic structure of montmorillonite varies depending on atomic substitutions within the crystalline network. This characteristic motivates changes on the nature and amount of the surface ions, as a consequence, on the cation exchange capacity, and indirectly on the layer-to-layer spacing. In general, depending on the nature of the surface ions, two types of montmorillonites can be found in the different geographic areas in the world; sodium and calcium. Therefore, the main purpose of the present study was to use the two types of montmorillonites in order to determine their effect on the chemical hybridization reactions of Nylon 6. The reaction mechanisms in both cases should be expected to be different since mono and bivalent ions cover the respective clay surfaces. A second purpose was to determine the influence of the different types of clay on the morphological characteristics of the hybrid products. The results were compared with those of a commercial reference. 


\section{MATERIALS AND METHODS}

\section{Nanoclays Preparation}

Samples for this work were a commercial, cation exchanged, reference (I24TL) from Nanocor U.S.A and two sodium $(\mathrm{BNaFT})$ and calcium $(\mathrm{BCaFT})$ local montmorillonites. In the last two cases, it was necessary to use refinement processes which consisted of grinding, sieving, and, where necessary, additional acid treatments in order to eliminate iron. The local montmorillonites were also homoionized with $\mathrm{NaOH}$, and then ion exchanged with amino dodecanoic acid (Sigma Aldrich Co.) in order to obtain the nanoclay precursors (Usuki JMR 1993) [12], (Usuki JMR 1993) [13].

\section{Hybrids Synthesis}

Hybrid synthesis was made in a Parr 4520 batch reactor using $\varepsilon$-caprolactam (Sigma Aldrich Co.) and $13 \mathrm{wt} \%$ aminocaproic acid (Sigma Aldrich Co.) as initiator. Before chemical reaction, montmorillonite monomer dilution was made in order to enhance the layer-to-layer dispersion using the monomer as a solvent. Clay dilution was made with $2 \mathrm{wt}$ $\%$ clay at $100{ }^{\circ} \mathrm{C}$ for $30 \mathrm{~min}$. The reaction conditions were automatically set in the reactor using nitrogen atmosphere at 21 psia of pressure. The hybrid products were water washed at $80{ }^{\circ} \mathrm{C}$ for $30 \mathrm{~min}$, and then vacuum dried at $80{ }^{\circ} \mathrm{C}$ for 48 hr.

\section{EXPERIMENTAL TECHNIQUES}

Wide angle X-ray diffraction (WAXD) patterns were obtained in a X'Pert Pro PANalytical X-ray diffraction equipment in reflection mode. The diffraction patterns were taken from plaques with dimensions $1 \times 1 \times 0.1 \mathrm{~cm}$. For the purpose of introducing specific thermal history, samples were first melted in a Mettler FP82HT hot-stage $\left(260{ }^{\circ} \mathrm{C} ; 3\right.$ $\mathrm{min})$, and then they were quickly transferred to another Mettler FP82HT hot-stage for isothermal crystallization.

Fourier Transform Infrared Spectroscopy (FTIR) was carried out in a Bruker Vector 22 FTIR spectrophotometer. FTIR was used to identify reaction products in amorphous films. These were obtained by quenching the melt onto cold metallic surfaces. Three neat Nylon 6 references from Polyscience Inc. were used for FTIR calibration purposes. The average sample thickness was $0.3 \mathrm{~mm}$ and the FTIR patterns were the result of 64 scans using a resolution of $4 \mathrm{~cm}^{-1}$.

Gel Permeation Chromatography (GPC) determinations were made in a Shimadzu LC-10AD high performance liquid chromatographer. This was coupled with UV-VIS and refractive index detectors. The GPC system was calibrated with the polystyrene standards of three different weightaverage molecular weights $(29,300 ; 44,000$; and 114,200 $\mathrm{g} / \mathrm{g}$-mol). Before column injection, which used chloroform as the mobile phase, the Nylon 6 samples were dissolved in a $4 \mathrm{v} / \mathrm{v} \%$ of 1,1,1,3,3,3-hexafluoro-2-propanol and chloroform solution both with chromatographic purity (Sigma Aldrich Co. U. S. A).

Differential scanning calorimetry (DSC) thermal traces were obtained with a Perkin-Elmer DSC-7 after temperature calibration with the indium and lead standards. Samples had an average weight of $8 \pm 1 \mathrm{mg}$ and were sealed within aluminum pans before positioning them in the sample holder where a constant flux of nitrogen was maintained. Samples were melted at $260{ }^{\circ} \mathrm{C}$ for $3 \mathrm{~min}$. and a nominal cooling rate of $500{ }^{\circ} \mathrm{C} / \mathrm{min}$ was used to quench the samples to the isothermal crystallization temperature, where they remained for $30 \mathrm{~min}$. The crystallization time was followed by linear heating at $10{ }^{\circ} \mathrm{C} / \mathrm{min}$ up to the equilibrium melting temperature of $260{ }^{\circ} \mathrm{C}$.

Small angle X-ray scattering experiments were made at the X27C beamline of the National Synchrotron Light Source, Brookhaven National Laboratory, USA. For this purpose, the bidimensional patterns were first obtained and then computer subtracted in order to obtain the X-ray scattering decay function. The sample to detector distance was $1400 \mathrm{~mm}$ and the specimens were the same as those used for WAXD measurements. The spectra were corrected for set up conditions, and the scattering was calibrated with $\mathrm{AgBe}$ as standard. The wavelength of the X-ray beam was $1.366 \AA$. And a three pinhole collimator system was used to reduce the beam size to $0.6 \mathrm{~mm}$ in diameter (Chu CR 2001) [14].

Transmission electron microscopy (TEM) was used to determine the degree of dispersion/exfoliation of nanoclays in the polymeric matrix. A JEOL 2000FX TEM electron microscope was used for this purpose with a voltage of $160 \mathrm{kV}$. All samples were cryo-microtomed at $-150^{\circ} \mathrm{C}$ using a diamond knife to obtain thick slices of $100 \mathrm{~nm}$ which were positioned on gold grids for experimental observations.

\section{SAXS Calculations}

The experimental reciprocal space curve was divided into three regions as reported elsewhere (Medellín-Rodríguez JPS B 1997) [15]. The low q side was corrected with the Debye model (Debye JAP 1957) [16] in order to obtain the extrapolated $\mathrm{I}(\mathrm{q}) \mid \mathrm{q}=0$. The intermediate $\mathrm{q}$ range was only smoothed thorugh a polynomial fit in order to minimize experimental deviations. The high I(q) $\mid q \rightarrow \infty$ side was corrected for deviations from an ideal Porod's law two phase system. The background intensity was considered polynomial (Vonk JAC 1975) [17], and as such was subtracted from the experimental data. The smoothing function was assumed sigmoidal (Ruland JAC 1971) [18]. The corrected intensity was extrapolated to Porod's region in order to locate $\mathrm{I}(\mathrm{q}) \mid \mathrm{q} \rightarrow \infty$. The long periodicity (L) was then calculated from Lorentz corrected plots of $\mathrm{Iq}^{2}$ vs $\mathrm{q}$.

\section{RESULTS AND DISCUSSION}

\section{Nanoclay Precursor Characterization}

As mentioned before, the nature of nanoclays indicates that the exchangeable ions on the surface of the clay platelets are either sodium $\left(\mathrm{Na}^{+}\right)$or calcium $\left(\mathrm{Ca}^{++}\right)$. The preferred form is sodium, although there are a number of calcium deposits in the world which can be used for the same purpose. Both types of montmorillonites were selected in this study in order to determine the contours of their behavior. In the first, $\mathrm{BNaFT}$ case, the cation exchange capacity was $136 \mathrm{meq} / 100$ $\mathrm{gr}$, and in the second, BCaFT case, it was $104 \mathrm{meq} / 100 \mathrm{gr}$. Fig. (1) shows the WAXD patterns of 200 mesh, as-received, and sodium exchanged, $\mathrm{BNaFT}$ and $\mathrm{BCaFT}$ montmorillonites. Here, the main impurities, quartz and wollestonite (see arrows), are observed. Such impurities were eliminated through a grinding/sieving process followed by flotation and filtration with water. 


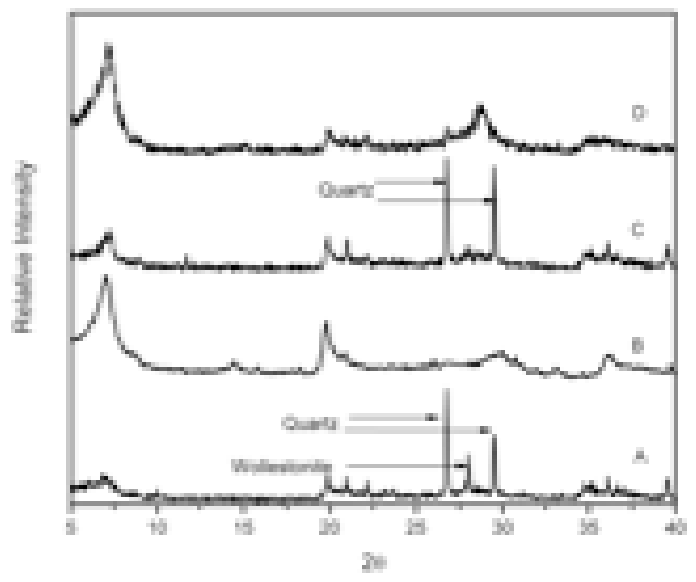

Fig. (1). WAXD patterns of: (A) as-received BCaFT; (B) sodium exchanged $\mathrm{BCaFT}$; $(\mathbf{C})$ as-received $\mathrm{BNaFT}$; and (D) sodium exchanged BNaFT.

After the indicated physical treatments, similar WAXD patterns were obtained in both cases independently of their origin. Fig. (2) shows the WAXD patterns after homoionization and ion exchange of the nanoclay precursors with onium surfactant (Usuki JMR 1993) [13]. The WAXD patterns of as-received, onium exchanged, commercial clay are also shown. These results indicate that the preparation methods and chemical treatments of the local clays essentially lead to similar crystallographic structures and periodicities (main reflection at $2 \theta=5^{\circ}$ ) as those of the reference. It has to be realized however that, during ion exchange, either one or two active centers must be involved depending on the nature of the exchangeable $\mathrm{Na}^{+}$and $\mathrm{Ca}^{++}$cations on the nanoclay surface (Valde CH 1992) [19]. Fig. (2) also indicates that the spacing of the treated precursors is slightly higher than the one of commercial nanoclay (see also Table 1). This effect is most probably due to the molecular length of the exchanged surfactant.

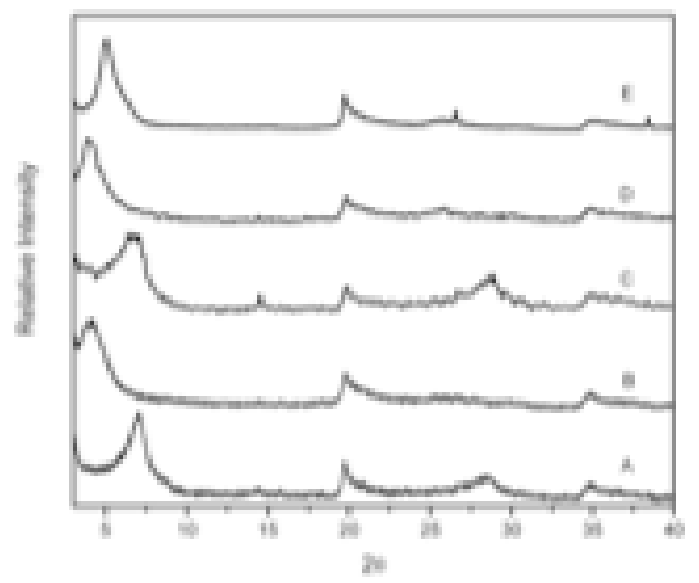

Fig. (2). WAXD patterns of: (A) sodium exchanged BCaFT; (B) onium exchanged BCaFT; (C) sodium exchanged BNaFT, (D) Onium exchanged BNaFT and (E) I24TL.

\section{Synthesis and Molecular Weight Characterization}

The synthesis of clay nanostructured Nylon 6 from $\varepsilon$-caprolactam has been reported before (Kojima JMR 1993)
[20]. The reaction mechanisms are similar as those involved in the preparation of Nylon 6 homopolymers (Schlack Patent 1941) [21], (Reimschuessel MR 1977) [22]. In the present study, neat Nylon 6 was obtained from $\varepsilon$-caprolactam using aminocaproic acid (13 wt \%) as initiatior and high reaction temperature (see reaction conditions later). In hybridization reactions, the ion exchanged montmorillonite (2 wt \%) was first suspended in the monomer at $100{ }^{\circ} \mathrm{C}$. The purpose was to disperse and swell the montmorillonite packets and as a consequence to increase the spacing within the nanoclay galleries. The reaction vessel was automatically set at specific reaction conditions using nitrogen atmosphere at $21 \mathrm{psi}$ of pressure. After chemical reaction, the hybrid products were washed with water at $80^{\circ} \mathrm{C}$ and vacuum dried for $48 \mathrm{hr}$ at $40{ }^{\circ} \mathrm{C}$.

Table I. SAXS Spacing of Nanoclay Hybrids

\begin{tabular}{|c|c|c|}
\hline Sample & $\begin{array}{c}\text { Sodium Exchanged } \\
\text { Spacing }(\mathbf{\AA})\end{array}$ & $\begin{array}{c}\text { Onium Exchanged } \\
\text { Spacing }(\mathbf{\AA})\end{array}$ \\
\hline \hline I24TL & - & 17.4 \\
\hline BNaFT & 12.4 & 20.3 \\
\hline BCaFT & 12.5 & 20.8 \\
\hline
\end{tabular}

The molecular weight of neat Nylon 6 homopolymers was determined through GPC. The molecular weight of the nanoclay-Nylon 6 hybrids can not be directly determined from GPC measurements because the nanoclay platelets are chemically attached to the polymeric macromolecules. Some authors have designed complex specific experimental techniques with the purpose to obtain the molecular weight of hybrid products (Fornes Macromol 2004) [23]. The combination of solvent-extraction/GPC methods has relatively similar uncertainties as other methods in determining the molecular weight of hybrids. For example, It is well known that the combination of solvent and high temperatures does not work efficiently during extraction and can induce degradation of the polymeric product (Reimschuessel MR 1977) [22]. Therefore, in the present study we used a simple FTIR based technique in order to determine the molecular weight of hybrids. This was based on the measurement of the intensity ratio between the carbonyl stretching vibration $(\mathrm{C}=\mathrm{O})$ at $1630 \mathrm{~cm}^{-1}$ which is present in both the cyclic $\varepsilon$-caprolactam monomer and the polymer, and the amide bending vibration $(\mathrm{CNH})$ at $1537 \mathrm{~cm}^{-1}$, which is present in the polymeric chain and is not present in the cyclic $\varepsilon$-caprolactam monomer. Therefore, the intensity ratio of these two vibrations decreases with increasing molecular weight of the polymeric product. Standard calibrations using neat polymers of different molecular weights were needed to generate a calibration curve where the hybrids intensity ratio was interpolated. A scheme of the polymerization process is shown in Fig. (3) where the gradual formation of the planar $\mathrm{CNH}$ groups is also shown.

Fig. (4) shows the FTIR calibration results of neat Nylon 6 homopolymers with different number-average molecular weights compared with the $\varepsilon$-caprolactam monomer. For these measurements, samples had an average thickness of 0.3 $\mathrm{mm}$, which was kept constant for normalization purposes. It 
is observed in the FTIR results in Fig. (4) that high molecular weights are characterized by lower peak ratios. Corresponding GPC measurement for all selected reaction conditions in this work are shown in Table 2 , where it is observed that extreme polymerization temperatures do not favor the formation of high molecular weights. It is also observed that the reaction time is not in direct correlation with the molecular weight. On the basis of these results, the best reaction conditions for neat Nylon 6 were determined as $260{ }^{\circ} \mathrm{C}$ and 6 $\mathrm{hr}$, which, as observed in Table II, rendered a numberaverage molecular weight of roughly $15500 \mathrm{~g} / \mathrm{g}$-mol. These reaction conditions were therefore used to synthesize the Nylon 6-nanoclay hybrids.

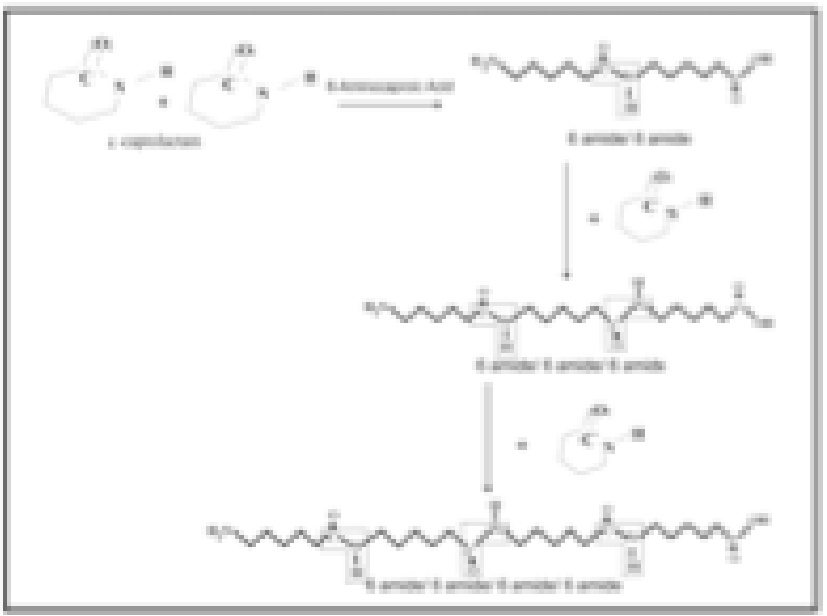

Fig. (3). Reaction mechanism during $\varepsilon$-caprolactam polymerization, the formation of the CNH FTIR sensitive planar groups is enhanced.

Table 3 shows the FTIR intensity ratio and the molecular weight results of hybrid products and neat Nylon 6. The results indicate that the molecular weight of hybrids has an average of $13,660 \mathrm{~g} / \mathrm{g}$-mol, although a molecular weight sequence $124 \mathrm{TL} \approx \mathrm{BNaFT}>\mathrm{BCaFT}$ can also be inferred.

\section{Morphological Studies}

The morphological characterization of semicrystalline polymers is often required in order to determine morphology/property relationships either with scientific or practical purposes. Typical morphological characterizations of semicrystalline polymers include crystallization and melting

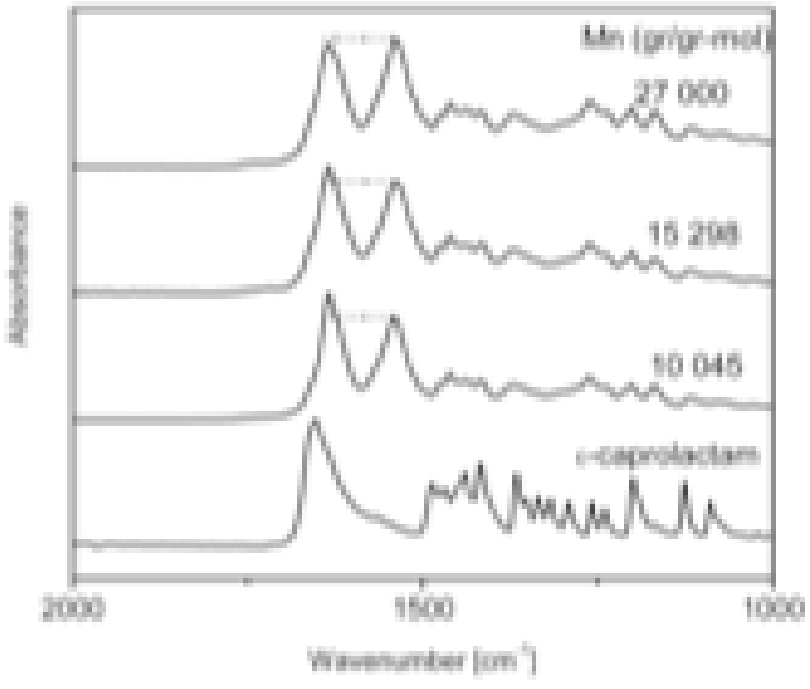

Fig. (4). FTIR results of reference $\varepsilon$-caprolactam, low molecular weight, intermediate molecular weight and high molecular weight Nylon 6. The number-average molecular weights are shown.

mechanisms. Fig. (5) shows the melting behavior of hybrids, after isothermal crystallization at $160{ }^{\circ} \mathrm{C}$, together with reference Nylon 6. Here, double melting behavior is the main characteristic of the thermal traces. The double melting behavior of neat Nylon 6 has been studied several times. Privalko et al. (Privalko PJ 1979) [24] related the first endotherm with bundle-like crystals which were formed in the last step of crystallization. Liberti and Wunderlich (Liberti JPS A 1968) [4] concluded that one endotherm was related to isothermal crystals and the other to recrystallized crystals. In a different approach, where more than two endotherms were observed, Medellín Rodriguez et al. (MedellínRodríguez Macromol 2004) [25] proposed that they had a morphological origin, although recrystallization, to a different crystal habit, was also considered. The number of melting endotherms was reported to vary from one to four depending on molecular weight and on the isothermal crystallization conditions (Medellín-Rodríguez JPS B 1997) [15]. The case of Nylon 6 hybrids isothermally crystallized at low temperatures $\left(160{ }^{\circ} \mathrm{C}\right)$ is shown in Fig. (5). Here, double melting behavior, similar to that of neat Nylon, 6 is observed. There is a small melting endotherm about $10{ }^{\circ} \mathrm{C}$ above the isothermal crystallization temperature, together with a more prominent endotherm which peaks at $219{ }^{\circ} \mathrm{C}$.

Table 2. GPC Molecular Weight of Neat Nylon 6 at Different Reaction Conditions

\begin{tabular}{|c|c|c|c|}
\hline Reaction Time (Hr) & Reaction Temperature $\left({ }^{\circ} \mathbf{C}\right)$ & Mn (g/g-mol) & Mw (g/g-mol) \\
\hline \hline 6 & 250 & 15317 & 22193 \\
\hline 6 & 260 & 15463 & 14315 \\
\hline 6 & 270 & 7092 & 21128 \\
\hline 7 & 260 & 73589 & 14563 \\
\hline 8 & 260 & 7341 & 14687 \\
\hline
\end{tabular}


The ultimate melting point of neat Nylon 6 is however a little higher than that of the nanocomposites as an indication that the molecular weight is lower than in any of the other cases, this is in spite that the same reaction conditions were used. There is also an overall tendency, in terms of the ultimate melting point, indicating that melting of I24TL is rather similar to that of BNaFT. BCaFT has however a lower melting point.

Table 3. FTIR Absorption Bands Ration and Molecular Weight Results

\begin{tabular}{|c|c|c|}
\hline Sample & $\mathbf{A}_{\mathbf{1}}\left(\mathbf{5 3 7} \mathbf{~ c m}^{-1}\right) / \mathbf{A}_{\mathbf{2}}\left(\mathbf{6 3 0} \mathbf{~ c m}^{-\mathbf{1}}\right)$ & $\mathbf{M n}(\mathbf{g} / \mathbf{g}-\mathbf{m o l})$ \\
\hline \hline Nylon6 & 0.687 & 16645 \\
\hline I24TL & 0.576 & 13472 \\
\hline BNaFT & 0.582 & 13650 \\
\hline BCaFT & 0.590 & 13864 \\
\hline
\end{tabular}

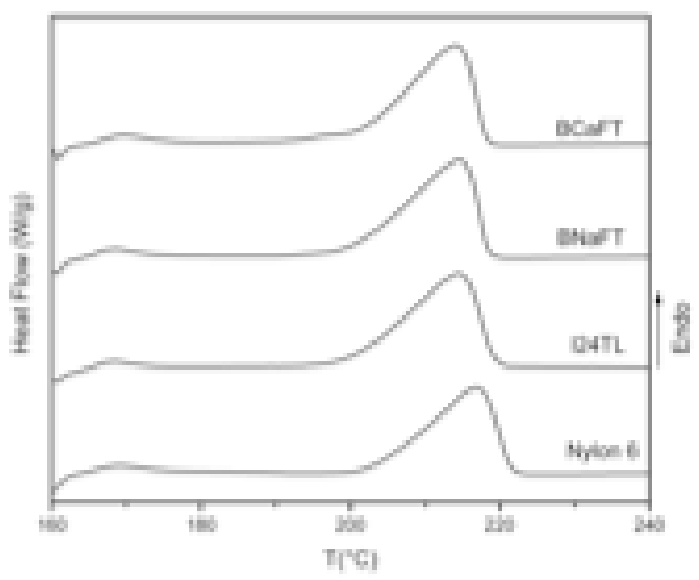

Fig. (5). DSC heating traces of Nylon 6, and Nylon 6-nanoclay hybrid products after isothermal crystallization from the melt $\left(\mathrm{Tm}=260{ }^{\circ} \mathrm{C} ; 3 \mathrm{~min}, \mathrm{Tc}=160{ }^{\circ} \mathrm{C} ; 30 \mathrm{~min}\right)$.

The melting traces of the neat reference and hybrid products, after isothermal crystallization at a higher temperature $\left(190{ }^{\circ} \mathrm{C}\right)$ are shown in Fig. (6). Here, as reported before (Vega-Díaz thesis 2003) [26], three melting endotherms characterize the melting behavior. It has been reported that the increase in molecular weight usually enhances the second melting endotherm of isothermally crystallized Nylon 6 (Medellín-Rodríguez Macromol 2004) [25]. This second melting endotherm enhancement is also progressively observed in the results of Fig. (6), where the increase of the second endotherm follows the sequence: $\mathrm{BCaFT}>\mathrm{BNaFT}$ $\approx \mathrm{I} 24 \mathrm{TL}$. Therefore, the previous DSC results can also be considered an indication that the molecular weight determinations through FTIR are relatively correct. This is considering for example that the sample (BCaFT) with the highest molecular weight had the highest second melting endotherm.

The WAXD results after isothermal crystallization at 160 ${ }^{\circ} \mathrm{C}$ are shown in Fig. (7). These indicate that only the $\alpha$ crystallographic form is formed (Medellín-Rodríguez Macromol 2004) [25]. The $\alpha$ crystal habit usually shows two symmetric diffraction peaks associated to the (200) and (002/202) crystallographic planes (Kyotani JPSP A 1972) [2]. It is however observed in neat Nylon 6 a slight disproportion in intensities of the (200), (002/202) diffraction peaks which can be assigned to the selected crystallization temperature. It has been reported before (Wu PES 2002) [8] that crystallographic plane disproportion is a manifestation of hybridization in Nylon 6 nanoclay hybrids. This is because the chemical attachment of the macromolecules to the nanoclay platelets induces the molecules to crystallize along a particular direction, usually normal to the substrate surface. Therefore, plane truncation of the (200) crystal planes is often reported in Nylon 6 hybrids (Wu PES 2002) [8] (Medellín-Rodríguez Macromol 2004) [25]. Assuming proportional degrees of plane truncation respect to the hybridization process, the results in Fig. (7) indicate that the degree of hybridization corresponds to the sequence $124 \mathrm{TL} \approx \mathrm{BNaFT}>\mathrm{BCaFT}$.

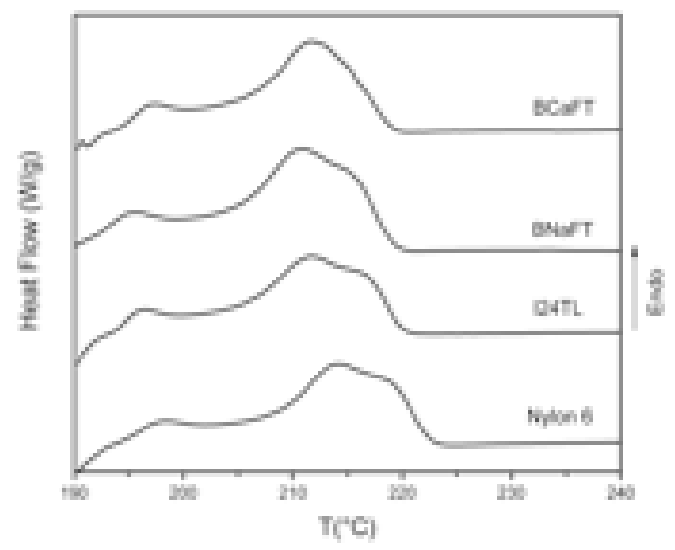

Fig. (6). DSC heating traces of reference neat Nylon 6, and Nylon 6-nanoclay hybrid products after isothermal crystallization from the melt $\left(\mathrm{Tm}=260{ }^{\circ} \mathrm{C} ; 3 \mathrm{~min}, \mathrm{Tc}=190^{\circ} \mathrm{C} ; 30 \mathrm{~min}\right)$.

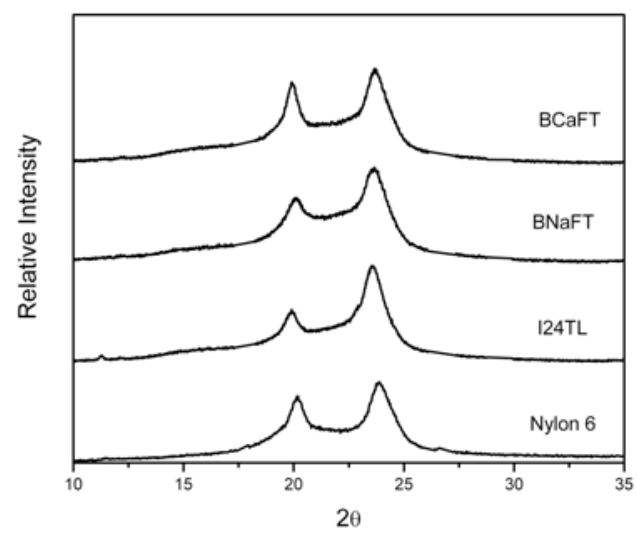

Fig. (7). WAXD patterns of reference Nylon 6, and hybrid products after isothermal crystallization at $160{ }^{\circ} \mathrm{C}$.

The plane truncation effects are enhanced when isothermal crystallization is carried out at $190{ }^{\circ} \mathrm{C}$, as shown in Fig. (8). In this case, the (200) diffracting planes slightly decrease in intensity in all cases.

As expected, due to plane truncation, the hybridization effect leads to lower values of crystallinity in the hybrids compared with the neat polymer as shown in Table 4 . 


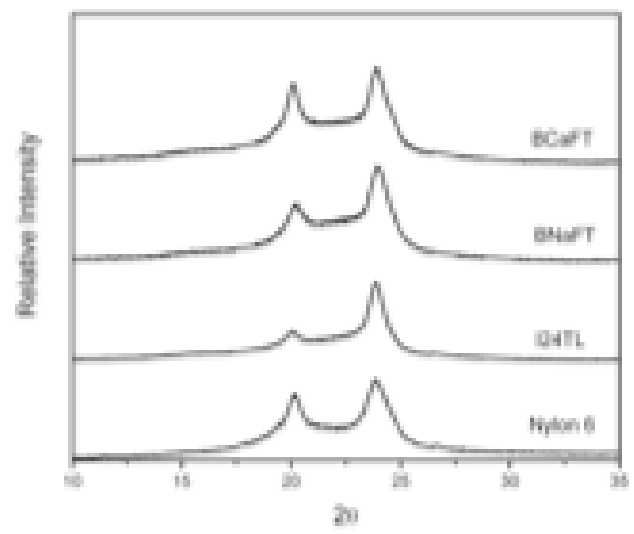

Fig. (8). WAXD patterns of reference Nylon 6, and hybrid products after isothermal crystallization at $190{ }^{\circ} \mathrm{C}$.

Table 4. SAXS/WAXD Characteristics of Reference Nylon 6 and Clay Nanostructured Composites

\begin{tabular}{|c|c|c|c|c|}
\hline Sample & $\mathbf{L}(\mathbf{A})$ & $\mathbf{C C}(\% \mathbf{w t})$ & $\begin{array}{c}\mathbf{X c}(\%) \\
\left(\mathbf{1 6 0}^{\circ} \mathbf{C}\right)\end{array}$ & $\begin{array}{c}\mathbf{X c}(\%) \\
\left(\mathbf{1 9 0}^{\circ} \mathbf{C}\right)\end{array}$ \\
\hline \hline Nylon6 & 82 & 0 & 55 & 53 \\
\hline I24TL & 88 & 2 & 39 & 35 \\
\hline BNaFT & - & 2 & 45 & 41 \\
\hline BCaFT & 89 & 2 & 54 & 50 \\
\hline
\end{tabular}

$\mathrm{L}=$ Spacing; $\mathrm{CC}=$ Clay content; $\mathrm{Xc}=$ Crystallinity.

Clay nanostructured hybrids are complex polymerization products in which more than one constitutive phase is present. The SAXS technique is useful to characterize crystalline phases, and particularly to quantify the constitutive lamellar crystals. Fig. (9) shows the SAXS results of samples after isothermal crystallization at $160{ }^{\circ} \mathrm{C}$ for $30 \mathrm{~min}$. The results indicate that only the neat polymer develops a well defined scattering maximum which emerges from the isotropic lamellar crystals. The lamellar periodicity in this case has a value of $8.2 \mathrm{~nm}$, indicating that lamellar crystals are rather thin (see also Table 4). Clay nanostructured samples on the other hand did not show well defined scattering maxima, although, there is a perceptible tendency to the formation of a scattering maximum in the sequence $\mathrm{BCaFT}$ $>124 \mathrm{TL}>\mathrm{BNaFT}$. If we consider that the scattering maximum is associated with unbounded polymer, another way of looking at these results is to assume that the lowest amount of the scattering maximum involves the highest amount of hybridization as is the case of BNaFT. This is consequently where the molecularly unbounded crystals must be in the lowest proportion. Therefore, the previous results can be considered an indication that the less efficient substrate to hybridize Nylon 6 is calcium nanoclay (BCaFT). Due to the crystallization temperature, which translates the scattering peak to the low q side in the X-rays decay function, it is not possible to observe the previous tendency after isothermal crystallization at $190^{\circ} \mathrm{C}$, as shown in Fig. (10).

The TEM micrographs in Fig. (11) give support to the previous propositions. It is observed in these micrographs good dispersion and nanoclay exfoliation in the $\mathrm{BNaFT}$ case, which is closely followed by I24TL. In the BCaFT case there is neither good clay dispersion nor exfoliation and it is also possible to observe some clear isotropic areas. These last are most probably related to molecularly unbounded polymer crystallization.

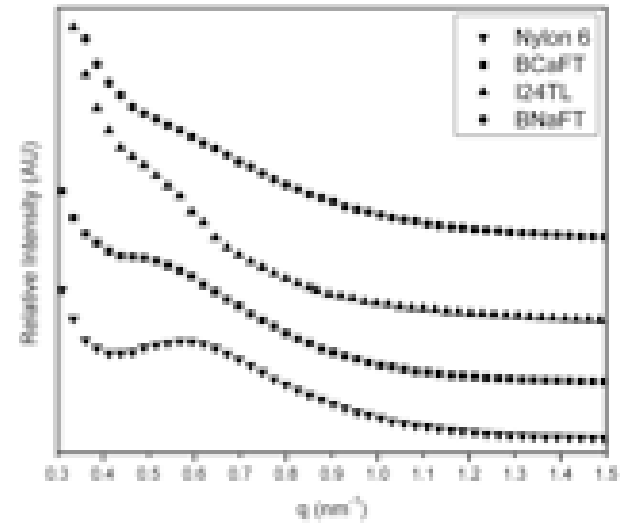

Fig. (9). SAXS decay intensity curves of reference Nylon 6 and hybrid products after isothermal crystallization at $160{ }^{\circ} \mathrm{C}$.

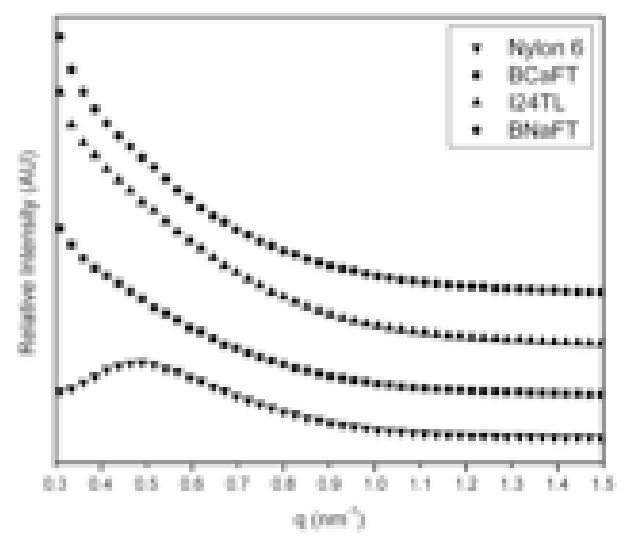

Fig. (10). SAXS decay intensity curves of reference Nylon 6 and of hybrid products after isothermal crystallization at $190{ }^{\circ} \mathrm{C}$.

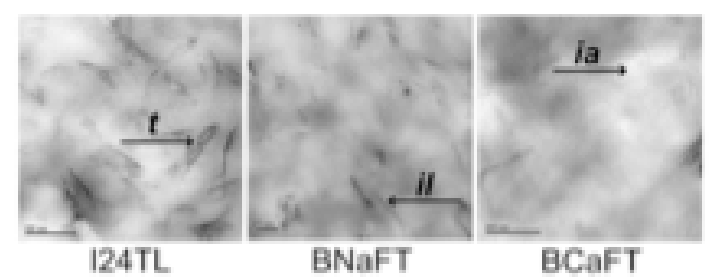

Fig. (11). TEM images of hybrid products showing tactoids (t), individual layers (il) and isotropic areas (ia).

\section{CONCLUSIONS}

Two different types of montmorillonites (sodium and calcium) and a commercial reference were used to synthesize Nylon 6 hybrids. The three types of nanoclay precursors had similar crystallographic structure and layer-to-layer spacing.

Under identical synthesis conditions, sodium, calcium, and commercial nanoclays rendered relatively similar molecular weights of hybrid products. 
Thermal analyses of the nanocomposites displayed the typical double and triple melting behavior observed in Nylon 6 . This indicated that the lamellar crystal morphology of both systems was similar. The melting behavior was in agreement with molecular weight determinations, although lower melting points were observed in neat Nylon 6 obtained under identical reaction conditions.

Crystallographic plane truncation, usually observed in nanoclay hybrids, was observed in all hybrid products although in different proportions. This was an indication that both sodium and calcium clay are useful for Nylon 6 hybridization. The closer plane truncation to commercial clay was however the sodium base clay precursor.

The SAXS results of isothermally crystallized samples at low temperatures indicated the presence of unbounded polymer with periodicities similar to those of neat Nylon 6. This was particularly the case of calcium and commercial clays. As for sodium clay, the polymer SAXS dispersion was almost absent as an indication of higher and more homogeneous hybridization.

\section{ACKNOWLEDGEMENTS}

This work was financially supported by the National Research Council of Science and Technology of Mexico (CONACYT) through grants U40177-Y and 57070. We also thank the Fund for Research Support (FAI-C06-FAI-1122.59) of UASLP, and the Academic Group CA36 of FCQ/UASLP. Special thanks are due to Professor Benjamin Hsiao for allowing the use of the X27C beamline at BNL.

\section{REFERENCES}

[1] Ke, Y.C.; Stroeve, P. Polymer-layered silicate and silica nanocomposites, Elsevier B.V.: Amsterdam, 2005.

[2] Kyotani, M.; Mitsuhashi, S. Studies on crystalline forms of Nylon 6. II. Crystallization from the melt. J. Polym. Sci. Part A-2, 1972, 10(2), 1497-1508.

[3] Gurato, G.; Fichera, A.; Grandi, F.Z.; Zannetti, R.; Canal, P.;Crystallinity and polymorphism of 6-polyamide. Die. Makromol. Chem., 1974, 175(3), 953-975.

[4] Liberti, F.N.; Wunderlich, B. Melting of polycaprolactam. J. Polym. Sci. Part A-2, 1968, 6(5), 833-848.

[5] Arakawa, T.; Nagatoshi, F.; Arai, N. Melting behavior and morphology of drawn Nylon 6. J. Polym. Sci. A-2, 1969, 7(9), 14611472.

[6] Valenti, B.; Bianchi, E.; Greppi, G.; Tealdi, A.; Ciferri, A. Bulk properties of synthetic polymer-inorganic salt systems. melting behavior of salted poly(caproamide). J. Phys. Chem., 1973, 77(3), 389-395.

[7] Itoh, T.; Miyaji, H.; Asai, K. Thermal properties of $\alpha$ - and $\gamma$-forms of Nylon 6. Japanese. J. Appl. Phys., 1975, 14(2), 206-215.
[8] Wu, T.M.; Chen, E.C.; Liao, C.S. Polymorphic behavior of Nylon 6/saponite and Nylon 6/montmorillonite nanocomposites. Polym. Eng. Sci, 2002, 42(6), 1141-115.

[9] Bertmer, M.; Wang, M.; Krüger, M.; Blümich, B.; Litvinov, V.M.; Van Es, M. Structural changes from the pure components to Nylon 6-montmorillonite nanocomposites observed by solid-state NMR. Chem. Mater., 2007, 19(5), 1089-1097.

[10] Nair, S.S.; Ramesh, C. Studies on the crystallization behavior of Nylon-6 in the presence of layered silicates using variable temperature WAXS and FTIR. Macromolecules, 2005, 38(2), 454-462.

[11] Zapata-Espinosa, A.; Medellín Rodríguez, F.J.; Stribeck, N.; Almendarez-Camarillo, A.; Vega-Díaz, S.; Hsiao, B.S.; Chu, B. Complex isothermal crystallization and melting behavior of Nylon 6 nanoclay hybrids. Macromolecules, 2005, 38(10), 4246-4253.

[12] Usuki, A.; Kawasumi, M.; Kojima, Y.; Okada, A.; Kurauchi, T.; Kamigaito, O. Swelling behavior of montmorillonite cationexchanged for $\omega$-amino acids by $\varepsilon$-caprolactam. J. Mater. Res., 1993, 8(5), 1174-1178.

[13] Usuki, A.; Kojima, Y.; Kawasumi, M.; Okada, A.; Fukushima, Y.; Kurauchi, T.; Kamigaito, O. Synthesis of Nylon 6-clay hybrid. $J$ Mater. Res., 1993, 8(5), 1179-1184.

[14] Chu, B.; Hsiao, B. S. Small-angle X-ray scattering of polymers. Chem. Rev., 2001, 101(6), 1727-1762.

[15] Medellín-Rodríguez, F.; Phillips, P.; Lin J.; Campos, R. The Triple Melting behavior of Poly(ethylene terepthalate); molecular weight effects. J. Polym. Sci. Polym. Phys. Ed., 1997, 35 (11), 1757-1774.

[16] Debye, P.; Anderson, H. R., Jr.; Brumberger, H. Scattering by an inhomogeneous solid. II. The Correlation Function and Its Application. J. Appl. Phys., 1957, 28(6), 679-683.

[17] Vonk, C.G. A general computer program for the processing of small-angle X-ray scattering data. J. Appl. Cryst., 1975, 8(2), 340341.

[18] Ruland, W. Small-angle scattering of two-phase systems: determination and significance of systematic deviations from Porod's law. J. Appl. Cryst., 1971, 4(1), 70-73.

[19] Valde, B. Introduction to clay minerals, Ed. Chapman \& Hall: London, 1992.

[20] Kojima, Y.; Usuki, A.; Kawasumi, M.; Okada, A.; Fukushima, Y.; Kurauchi, T.; Kamigaito, O. Mechanical properties of Nylon 6clay hybrid. J. Mater. Res., 1993, 8(5), 1185-1189.

[21] Schlack, P. Preparation of Polyamides. U.S. Patent 2241321, May 6, 1941.

[22] Reimschuessel, H.K. Nylon 6: Chemistry and mechanisms. Macromol. Rev., 1977, 12, 65-139.

[23] Fornes, T.D.; Hunter, D.L.; Paul, D.R. Nylon-6 nanocomposites from alkylammonium-modified clay: The role of alkyl tails on exfoliation. Macromolecules, 2004, 37(5), 1793-1798.

[24] Privalko, V.P.; Kawai, T.; Lipatov, Y.S. Crystallization of filled Nylon 6. I. Heat capacities and melting behavior. Polym. J., 1979, 11(9), 699-709.

[25] Medellín-Rodríguez, F.J.; Larios López, L.; Zapata-Espinoza, A.; Dávalos-Montoya, O.; Phillips, P.J.; Lin, J.S. Melting behavior of polymorphics: Molecular weight dependence and steplike mechanisms in Nylon-6. Macromolecules, 2004, 37(5), 1799-1809.

[26] Vega-Díaz, S.M. Thesis, University of San Luis Potosí, México; 2003. 